\title{
A RARE CASE OF MASSIVE ENVENOMATION OF HONEY BEES WITH ANAPHYLAXIS
}

\author{
Rahul Valisetty¹, P. N. Venkatarathnamma², B. N. Raghavendra Prasad ${ }^{3}$, Uphar Gupta4
}

\section{HOW TO CITE THIS ARTICLE:}

Rahul Valisetty, P. N. Venkatarathnamma, B. N. Raghavendra Prasad, Uphar Gupta. "A Rare Case of Massive Envenomation of Honey Bees with Anaphylaxis". Journal of Evolution of Medical and Dental Sciences 2014;

Vol. 3, Issue 54, October 20; Page: 12513-12516, DOI: 10.14260/jemds/2014/3657

\begin{abstract}
Honeybee sting incidents are quite common in India with $69 \%$ population living in rural areas. Death due to honeybee stings is quite rare. The usual manifestation of a honeybee sting is either a local reaction or a systemic reaction of anaphylaxis or massive envenomation when a large number of honeybees are stung. Massive envenomation by honeybees usually results in Acute Kidney Injury and Cardiac arrest. Here is a case of 35 year old male patient who presented with multiple honeybee stings of around one hundred and fifty resulting in massive envenomation and anaphylaxis, who went in to acute renal failure and had a cardiac arrest despite the supportive measures.
\end{abstract}

KEYWORDS: Envenomation, honeybee stings.

INTRODUCTION: Honeybee sting incidents are quite common in India with many people living in rural and tribal areas. The species of honeybees present in India are Apisdorsata - Rock bee, Apisceranaindica - the Indian hive bee, Apisflorea - the little bee, Apismellifera - the European or Italian bee. Most of the toxic bites are from Apisdorsata - the rock bee that is ferocious and present all over India. ${ }^{1}$ Honeybees are unique, in the sense that they leave their barbed stinger after stinging, and subsequently die after one sting because they disembowel themselves. The stinger continues to inject the venom by a valve system even after the bee leaves the site of sting and not by external compression of the sac. ${ }^{2}$

Allergens constituting the venom include vasoactive amines, small polypeptides and enzymes. Histamine, mast cell degranulating peptide, phospholipase $\mathrm{A}_{2}$ (PLA $)$, hyaluronidase, acid phosphatase and melittin are the important constituents. ${ }^{3,4}$ The bee sting may lead to local reaction, systemic allergic responses or anaphylactic reactions. Although most stings cause only minor problems like local reactions, others may cause serious problems like rhabdomyolysis, intravascular coagulation, cerebral hemorrhage, acute pulmonary edema, acute renal failure (ARF) and even death.5,6 Massive bee stings may lead to Envenomation. The incidence of anaphylaxis caused by insect sting has been estimated to be $1 \%$ in children and $3 \%$ in adults. ${ }^{7}$

Local reactions mainly include pain, edema, pseudo pustule and secondary infections. Melittin a toxin present in bee venom is responsible for pain. Histamine and other biogenic amines also contribute to pain \& itching. ${ }^{8} \mathrm{~A}$ large local reaction is confined to general area of sting, but over 24 48 hours it develops into much larger area. A large local reaction is IgE mediated and therefore is an allergic response.

Systemic allergic responses or Anaphylaxis include mild anaphylactic reactions which are pure cutaneous skin responses or involving other systems like gastrointestinal, nervous system or cardiopulmonary system. Severe anaphylaxis reactions involving cardiopulmonary system is seen in $<1 \%$ people. Anaphylaxis may be preceded by generalized itching, edema with stridor, shock, loss of consciousness and death. They progress rapidly over 1 to 30 minutes. 
The symptoms may recur after 4 to 6 hours despite the treatment in many cases. Reaction is delayed as much as 6 days. It occurs due to rhabdomyolysis and myoglobinuria.

Bees release large amount of venom, $50-140 \mathrm{mcg} / \mathrm{sting}^{6}$ The estimated lethal dose is approximately 20 stings/kg in most mammals. ${ }^{2}$

There are several reports from India and abroad, of patients developing rhabdomyolysis, acute renal failure, Guillain-Barre syndrome, myasthenia gravis and coagulopathy following multiple bee stings. ${ }^{9-12}$ Kidney failure and cardio toxicity cause most toxic bee sting deaths.

CASE REPORT: A 35-year-old male patient presented to the emergency room with history of multiple honey beestings. Patient bystanders give history that their family went to a temple on hill in a tractor when a swarm of bees attacked them. Many of them fled the place, later they realized this particular person missing from the family and late in the evening found him lying unconscious at the same hill site, almost 7 hours after the honeybee attack. There was no known past history of bee stings.

On examination, patient was unconscious with GCS of 3/15. Peripheries were cold with generalized non-pitting edema, wheals; multiple bee sting marks (more than150) were present all over the body more on the exposed parts of face, neck and hands. Facial edema was present involving lips and periorbital areas. Pulse and blood pressure were not recordable, respiratory rate was 40 cycles per minute and was shallow. There were no external injuries.

Cardiovascular examination revealed heart rate of 100 per minute S1 and S2 present with no S3 gallop, no pericardial rub, and no murmurs. Respiratory system auscultation was bilateral normal vesicular breath sounds and no crepitation can be made out. No organomegaly noted on per abdominal examination.

Honeybee stings were removed by plucking as well as scraping in casualty. A diagnosis of massive envenomation by multiple bee stings with severe systemic reaction of grade IV on Muller grading system was made and patient was immediately put on ventilator support without any delay. Fluid resuscitation was initiated along with ionotropic support by Noradrenaline and Dopamine. A stat dose of injection Hydrocortisone, injection pheniramine, injection Tetanus toxide, parenteral antibiotics were given. Bladder catheterization was done and $50 \mathrm{ml}$ of urine output was noted.

Lab investigations revealed hemoglobin $-12 \mathrm{gm} \%$, WBC $-16,000 / \mathrm{mm}^{3}$ with Neutrophils of $90 \%$, blood sugar - $130 \mathrm{mg} / \mathrm{dl}$, blood urea - 50mg/dl, Serum Creatinine $-2 \mathrm{mg} / \mathrm{dl}$. HIV test was negative. ECG showed sinus tachycardia. Bedside 2D echo showed no Regional Wall Motion Abnormality, No pericardial effusion. CT brain was normal study.

Despite the ventilatory support, fluid resuscitatory measures and ionotropic support even after 6 hours of admission BP was not recordable, Tachycardia and coma persisted, urine output did not improve. Patient had a sudden cardiac arrest and could not be revived.

DISCUSSION: This patient was brought to hospital 7 hours following the mass bee stings and he was in anaphylactic shock respiratory depression and deep comatose state.lab reports revealed elevated WBC and features of acute renal failure.

Systemic allergic reactions are more often seen in those with occupational risk. Skin tests are needed for those individuals who are candidates for immunotherapy. ${ }^{13}$ Large local reactions are usually treated with topical applicants. Antihistamines, leukotriene receptor antagonists, oral steroids are the main line of treatment. 
Systemic allergic response usually benefit from allergy testing and subsequent desensitization immunotherapy. Venom Immuno Therapy greatly reduces the risk of systemic reactions in stinging insect-sensitive patients with an efficacy of up to $98 \% .{ }^{14}$ Desensitization venom immunotherapy entails the administration of gradually larger doses of venom at regular intervals over 6 months.

Repeated exposure to the venom leads to a change in the way the regulatory $\mathrm{T}$ cells react to particular offending antigen. These $T$ cells instruct the $B$ cells to switch antibody production against venom proteins from allergic IgE to non-allergic IgG. Venom immunotherapy or allergy shots markedly reduce the risk of a systemic reaction to re-stings. After immunotherapy has been undertaken for five years, the risk of a systemic reaction is about $10 \%$ to a re-sting.

Even though desensitization therapy can be used for prophylaxis, it is of use only in professional beekeepers who are regularly exposed and a higher risk of stinging. However general population is protected by supportive therapy only. Thus this rare case of multiple honey bee stings leading to death one such scenario where massive envenomation leading to acute renal failure and cardiac arrest.

\section{REFERENCES:}

1. TNAU Agritech portal www. Agritech.tnau.ac.in.

2. Balamurgan N, Senthilkumaran S, Thirumalaikolundusubramanian P. Mass envenomation by honey bee-speed thrills. J Emerg Trauma Shock. 2010; 3: 420-1.

3. Krishna MT, Ewan PW, Diwakar L, et al. Diagnosis and management of hymenoptera venom allergy: British Society for Allergy and Clinical Immunology (BSACI) guidelines. Clinical and Experimental Allergy. 2011; 41 (9): 1201-20.

4. Burns DA. Diseases caused by arthropods and other noxious animals. In: Burns DA, Breathnach SM, Cox NH, Griffiths CEM (Eds). Rook's Textbook of Dermatology, 8th edition. Blackwell Publishing. 2009. pp. 38.2-4.

5. Hiran S, Pande TK, Pani S, Gupta R, Vishwanathan KA. Rhabdomyolysis due to multiple honey bee stings. Postgrad Med J. 1994; 70: 937. [PMC free article] [PubMed].

6. Truskinovsky AM, Dick JD, Hutchins GM. Fatal infection after a bee sting. Clin Infect Dis. 2001; 32: E36-8. [PubMed].

7. Golden DB. Stinging insect. Am Fam Physician. 2003; 67 (12): 2541-6.

8. Meier J, White J. (1995). Clinical toxicology of animal venoms and poisons. CRC Press, Inc. ISBN 0-8493-4489-1.

9. Poddar K, Poddar SK, Singh A. Acute polyradiculoneuropathy following honey bee sting. Ann Indian Acad Neurol. 2012; 15 (2): 137-8.

10. Ceyhan C, Ercan E, Tekten T, et al. Myocardial infarction following a bee sting. Int J Cardiol. 2001; 80 (2-3): 251-3.

11. Vetter RS, Visscher PK, Camazine S. Mass envenomations by honey bees and wasps. West J Med. 1999; 170 (40): 223-7.

12. Jain J, Banait S, Srivastava AK, et al. Stroke intracerebral multiple infarcts: rare neurological presentation of honey bee bite. Ann Indian Acad Neurol. 2012; 15 (2): 163-6.

13. http://www.apiindia.org/medicine_update_2013/chap92.pdf. 
14. Portnoy JM, Moffit JE, Golden DB, et al. Joint task force on practice parameters for allergy and immunology. J Allergy Clin Immunol. 1999; 103: 963-80.

\section{AUTHORS:}

1. Rahul Valisetty

2. P. N. Venkatarathnamma

3. B. N. Raghavendra Prasad

4. Uphar Gupta

\section{PARTICULARS OF CONTRIBUTORS:}

1. Post Graduate Student, Department of General Medicine, Sri Devaraj Urs Medical College, Tamaka, Kolar, Karnataka.

2. Professor, Department of General Medicine, Sri Devaraj Urs Medical College, Tamaka, Kolar, Karnataka.

3. Professor, Department of General Medicine, Sri Devaraj Urs Medical College, Tamaka, Kolar, Karnataka.
4. Post Graduate Student, Department of General Medicine, Sri Devaraj Urs Medical College, Tamaka, Kolar, Karnataka.

\section{NAME ADDRESS EMAIL ID OF THE} CORRESPONDING AUTHOR:

Dr. Rahul Valisetty, Room No. 224, PG Men's Hostel, Sri Devaraj Urs Medical College, Tamaka-563101, Kolar, Karnataka. Email: rahulvalisetty@gmail.com

Date of Submission: 03/06/2014. Date of Peer Review: 04/06/2014. Date of Acceptance: 11/10/2014. Date of Publishing: 20/10/2014. 